\title{
PRODUCCIÓN DE CONOCIMIENTO EN LA UNIVERSIDAD
}

\author{
Juan Manuel Garrido
}

Universidad Alberto Hurtado

\begin{abstract}
RESUMEN: En este ensayo, el autor arguye que la producción de conocimiento es impredecible e indomesticable, y requiere, por lo tanto, una autonomía propia. De esta manera, no puede ser sometida por el poder sin destruir su propia naturaleza, aunque sí necesita del poder para hallar el espacio institucional necesario para desenvolverse. Como este espacio institucional es, en las sociedades contemporáneas, la universidad, las necesidades propias de la producción de conocimiento deben ser consideradas en los modelos de financiamiento y administración universitario si se quiere que esta producción tenga éxito. Palabras Clave: universidad, investigación, producción de conocimiento, poder, modernidad.
\end{abstract}

Juan Manuel Garrido. Doctor en filosofía por la Universidad Marc Bloch de Strasbourg, Francia. Director del doctorado en filosofía en la Universidad Alberto Hurtado. Email: jgarrido@uahurtado.cl.

El autor quiere señalar: "El presente texto reúne resultados de un seminario dictado junto al profesor Eduardo Molina Cantó en el Departamento de Filosofía de la Universidad Alberto Hurtado, durante el segundo semestre de 2015. El seminario contó con la participación de Boris Núñez y del profesor Jorge Costadoat. Inútil agradecerles detalladamente lo que el texto les debe. Lo expuse parcialmente en el simposio sobre el concepto de universidad organizado por Enzo Solari y Javier Wilenmann en el IV Congreso Nacional de Filosofía de la Achif, entre el 26 y el 30 de octubre de 2015, así como en la mesa 'Educación y democracia' en el coloquio 'Cosmopolitismo, globalización y revueltas locales', organizado por Aïcha Messina en el Instituto de Humanidades de la Universidad Diego Portales, el 16 de diciembre de 2015. Agradezco, por último, los comentarios que Luis Felipe Alarcón, Matías Bascuñán, Víctor Ibarra B., Daniel Silva y Nicolás Trujillo hicieran al manuscrito". 


\section{PRODUCTION OF KNOWLEDGE IN THE UNIVERSITY}

ABSTRACT: In this essay, the author argues that the production of knowledge is unpredictable and cannot be domesticated, and therefore, requires its own autonomy. Thus, it cannot be submitted by the powers that be without destroying its own nature, but it does need the powers that be to find the institutional environment necessary for its development. Since this institutional environment is, in contemporary societies, the University, the particular requirements of the production of knowledge must be considered in University financing and administration models if this production is to succeed.

KeYwORDS: University, research, production of knowledge, power, modernity.

$\mathbf{P}$

or razones históricas y económicas de índole variada, las sociedades contemporáneas les encargan a sus universidades la implementación y el cultivo de sistemas de producción de conocimiento o investigación. La investigación es, sin embargo, sólo una parte del quehacer universitario, que en la práctica incluye formación de profesionales y capacitación técnica, ejecución de idearios sociales, emprendimiento económico privado, desarrollo de bienes públicos, y más. La discusión acerca de si esta parte es además necesaria para el desarrollo del todo o si al menos puede ser funcional a este desarrollo, y en cualquier caso no dificultarlo, es muy importante desde el punto de vista de la administración universitaria.

La percepción de la naturaleza y relevancia de la investigación varía enormemente entre las distintas casas de estudio. Pesan las miradas sobre su aptitud para ajustarse a objetivos estratégicos, el costo y beneficio de la inversión en equipos humanos y no humanos, la eventual repercusión en la calidad de la docencia y en las actividades de gestión (por la obtención de recursos externos y por las acreditaciones), el fortalecimiento de los vínculos con el medio y la extensión, la imagen pública y el capital ideológico, entre otros.

Pero existe además un debate que se da al exterior de la universidad, y que se relaciona con el reconocimiento social y las condiciones de posibilidad, tanto ideológicas como materiales, de la universidad misma como institución económica y social, y su idoneidad para implementar los sistemas de producción de conocimiento requeridos por la sociedad. 
Este debate pone en movimiento preguntas bastante más radicales que las que competen a la administración universitaria. En general, conciernen la definición de conocimiento y la percepción de su utilidad, en particular el costo y beneficio de producirlo al interior de instituciones - las universidades y, en otros países, escuelas e institutos tecnológicos- que mantienen, o al menos reclaman para sí, grados avanzados de autonomía respecto de la autoridad política y estatal y respecto de diversos actores económicos, pese a la existencia de mecanismos eficaces para controlar, estimular o inhibir de manera indirecta el desarrollo de la investigación y de formas determinadas de trabajo. Incluso, una vez admitida - por inercia o como resultado de una reflexión- la necesidad del conocimiento, y una vez aceptado su establecimiento en la universidad, subsisten preguntas relativas a las universidades mismas: qué son y para qué existen, si podrían haberlas puramente docentes o si el conocimiento que en ellas se produce obedece a fines claros y relevantes para la sociedad.

El siguiente trabajo analiza algunos de los conceptos que están a la base de la discusión sobre la naturaleza, el sentido y la utilidad de la universidad y de la producción de conocimiento en ella. Mi propósito es contribuir al espacio conceptual en que se desenvuelven los debates nacionales. ${ }^{1}$ No me asiste un afán normativista o prescriptivo, aun cuando mis análisis transparenten algunas opiniones — de las que no necesariamente soy consciente - de ese orden. El recorrido que propongo es simple. Quiero definir qué es producción de conocimiento y qué universidad; cuáles son las condiciones y cuál el alcance de la producción de conocimiento en la universidad; qué cabe esperar de ésta y cuáles son algunos de los principales desafíos que enfrenta una política pública que quiere articular de modo satisfactorio investigación y educación superior. Este recorrido no pasará por alto un elemento muy relevante para captar la lógica con que la sociedad entiende sus relaciones internas, y que condiciona el cultivo del conocimiento en ella, aunque dicho elemento suele ser esquivo, si no irreductible, al análisis filosófico, en la medida en que trasciende por definición el campo del mero concepto y de la mera esencia. Me refiero, obviamente, al poder.

${ }^{1}$ Me refiero a la discusión que se lleva a cabo actualmente en el contexto de las reformas a la educación superior impulsadas por el gobierno de Michelle Bachelet. 


\section{PRODUCCIÓN DE CONOCIMIENTO}

"Producción" es el proceso por el cual se ejecuta el conjunto de componentes definitorios de una cosa natural, social o ideal. Supone la determinación de los mecanismos que permiten el control y manipulación, intelectuales o empíricos, de la identidad de la cosa. Más: supone que tales mecanismos agotan la identidad de la cosa o que ésta es un sistema causal. Tomo la palabra "producción" en un sentido que abarca tanto lo que los griegos llamaban arte y técnica (techné), como fabricación o creación (poiesis) y curso natural de las cosas (physis). La definición que propongo incluye objetos de gran abstracción (por ejemplo, idealidades puras empleadas para modelar procesos naturales o investigadas a su vez en su estructura lógica) y entidades materiales dispares como los objetos tecnológicos (un par de zapatos o un teléfono celular), los hoyos negros, los movimientos sociales, las políticas públicas; en suma, cualquier fenómeno cuya identidad se establece de acuerdo con mecanismos que controlan intelectual o empíricamente su generación y sus propiedades. La definición excluye, sin embargo, el ámbito de la acción libre (praxis), que se define por oposición a la causalidad inherente a la idea de producción y que escapa a la práctica de la objetivación exacta, natural o social. Doy por descontado que el concepto de "producción" es una categoría de nuestra inteligencia, una forma que posibilita y a la vez condiciona nuestro acceso a la realidad, y no una estructura de ésta tal como se revelaría si se la pudiera considerar con independencia de nuestro modo de comprenderla (o tal como es "en sí").

"Conocimiento" es el proceso por el que se determinan los componentes definitorios de una cosa o, lo que es lo mismo, las reglas de su producción. La palabra "conocimiento" se refiere a veces al resultado de este proceso, es decir, al sistema normativo (eîdos o télos) con el que identificamos la cosa y que nos instruye sobre los mecanismos de su producción, control o manipulación. Un paper en cualquier área es, justamente, un instructivo de este tipo. Es indiferente qué clase de objetos consideremos, si naturales, sociales o ideales; es indiferente qué disciplinas o subdisciplinas se involucren en la determinación de los objetos; es indiferente en qué nivel situemos su estructura (subatómico, atómico, molecular, macromolecular, celular, multicelular, sistémico, cognitivo, social, semántico, lógico, etcétera), y la complejidad requerida para la 
ejecución de las reglas que los definen. El conocimiento es siempre el establecimiento de sistemas normativos definitorios de procesos productivos.

"Producción de conocimiento" es de índole y estatuto diferente tanto de la producción como del conocimiento de un objeto. La producción de conocimiento se distingue de cualquier producción humana por el hecho de que no se conoce de antemano la naturaleza de la cosa - eîdos o télos- que se desea producir y, por lo tanto, que debe guiar el proceso productivo. No sabemos qué será producido. De hecho, producir conocimiento es producir la identidad de una cosa por primera vez, engendrar un sistema normativo que puede luego convertirse, eventualmente, en el fin que guía un proceso productivo. Nada guía, empero, al proceso productivo de conocimiento. En otras palabras, la producción de conocimiento no es objeto de conocimiento. Un conocimiento que presumiera conocer el conocimiento - lo que hasta bien entrado el siglo pasado algunos filósofos llamaban teoría del conocimiento- y por lo tanto aislar y sistematizar los elementos que componen al conocimiento mismo, como si éste fuera a su vez objeto del conocimiento, culminaría ya sea en un círculo vicioso, ya sea en una regresión al infinito. Esto, porque o bien nos vemos obligados a dar por conocido en qué consiste (a saber: en una estructura normativa, productiva, en suma, un objeto del conocimiento), o bien tarde o temprano el análisis dejará pendiente la definición del sentido o metasentido en que el "conocimiento" conoce u objetiva el conocimiento. La producción de conocimiento no es, ella misma, objeto de conocimiento, en ningún sentido de la expresión. ${ }^{2}$

Si no conocemos el fin de lo que queremos producir, y la producción de conocimiento no es, ella misma, objeto de conocimiento, entonces no podemos determinar de antemano los medios eficientes, agentes, materiales y formales que son requeridos para la producción de conocimiento; por ejemplo, qué disciplinas, métodos, instrumentos, espacios, modelos, estilos, investigadores, equipos, etcétera, deben ser convocados en un determinado proceso de conocimiento. Para la desgracia de los ad-

${ }^{2}$ Seguiré usando la expresión "producción de conocimiento" sólo por costumbre, pero con ella me refiero a un tipo de actividad intransitiva, que no se confunde ni con una producción ni con un conocimiento. Confío en que los riesgos que pueda traer este abuso de lenguaje serán cada vez anulados por el contexto. 
ministradores y economistas del conocimiento, no es posible especificar de antemano las actividades, soportes institucionales y agentes que son definitorios de la producción de conocimiento. Diremos que, por el contrario, ésta supone determinados sistemas que, sin ser ellos mismos objetos de conocimiento, posibilitan una exposición a lo no producido, a lo no pensado o a lo no conocido, sin la cual la producción de conocimiento simplemente no ocurriría. Me refiero a la existencia de sistemas y procesos de aprendizaje, de formación, de estudio, de experimentación, de exploración, de ensayo; en suma, de exposición a lo desconocido. Formar, cultivar, estudiar, experimentar, explorar, ensayar no es lo mismo que instruir. Instruir significa transmitir sistemas normativos conocidos (según Aristóteles, es un criterio que permite reconocer al que ya sabe algo $)^{3}$. Instruir no es exponer a lo desconocido. ¡Lo que no quiere decir que sea posible exponerse a lo desconocido sin recibir instrucción! Para exponerse a lo desconocido hay que estar al límite de lo conocido. ${ }^{4}$

\section{VIDA, PODER Y PRODUCCIÓN DE CONOCIMIENTO}

La producción de conocimiento es un fenómeno ligado a la vida humana, y quizás a la vida en general. La primera frase de la Metafísica de Aristóteles dice: "Todos los hombres desean por naturaleza producir conocimiento". Esta célebre afirmación no transparenta un presupuesto antropológico. Se trata de una observación de sentido común con la que todos, desde Platón a Marx o Nietzsche, deberían estar de acuerdo: vivir consiste en producir los medios de vivir, y producir los medios de vivir — se entiende: mientras se vive, mientras se está en el trance de vivir, de mantenerse en vida, de inventar las maneras de no morir- nos expone a lo desconocido. Hasta cierto punto, vivir es estar necesitado de producir conocimiento. El conocimiento no es algo que buscamos después de que las necesidades básicas y materiales de la vida sean satisfechas, sino a la vez; esto es, implementamos sistemas para la producción de conocimiento en vistas de producir la vida.

${ }^{3}$ Aristóteles, Metafísica, libro A.

${ }^{4}$ La producción de conocimiento es un proceso histórico que supone la referencia constante a la tradición que transmite conocimientos y problemas. La formación de un investigador implica siempre, en cierto grado, la formación de una conciencia histórica. 
Y es que la vida - hablo de una idea, es decir, de un horizonte de sentido producido históricamente por el ser humano, no de una realidad en sí misma existente en el océano sin nombre de una naturaleza bruta o de un cielo verdadero- ha sido ella misma entendida como una actividad productiva, una producción de sí (autoproducción, autopoiesis). A tal punto, en verdad, que la idea de vida suministra quizás el prototipo principal de todo concepto de producción. La idea de vida no es la de una cosa, una sustancia, una entidad, una causa, ya sea alma, Dios, élan vital, genoma, etcétera. Corresponde a la idea de un modo de ser de entes definidos por tener-que-ser, por la acción de no dejar de ser lo que están siendo. Una piedra no está abandonada a la tarea de tener que ser, de cuidar de sí para no dejar de ser lo que es por naturaleza; un ser vivo, en cambio, es todo entero respuesta al problema de ser, de no dejar de ser lo que está siendo, de cuidar de sí como ser vivo. Los fenómenos vitales son actividades que ponen de manifiesto la tarea de ser (metabolismo, desarrollo, reproducción, evolución, comunicación, cognición); son actividades que revelan que ser, en el caso del ser vivo, es tener que ser. Vivir es producir la diferencia entre ser y no ser o entre ser y dejar de ser. El ser o estar vivo del ser vivo consiste en la producción de esta diferencia. La vida es la idea de una producción de sí como diferencia o como ser o como tarea de no dejar de ser en el proceso de nutrirse, crecer, reproducirse, organizarse, conocer... 5

El ser vivo siempre puede dejar de ser. Por eso es tarea de ser. La vida puede dejar de ser porque la vida misma, en sí misma, consiste en poder-vivir. La posibilidad de dejar de ser o la mortalidad es definitoria de la vida. No hay vida inmortal. Vivir es poder-vivir, es decir, podermorir. La vida no es: la vida puede. $Y$ entonces puede dejar de poder. ${ }^{6}$ El fenómeno de la vida es un fenómeno de poder.

¿Qué es, en sí mismo, el poder? La pregunta está mal planteada porque el poder no es algo cuya naturaleza o estructura normativa podemos describir como describimos en general un objeto. Sin duda

${ }^{5}$ Más sobre el concepto de vida en Juan Manuel Garrido, On Time, Being \& Hunger - Challenging the Traditional Way of Thinking Life (New York: Fordham University Press, 2012).

${ }^{6}$ Martin Heidegger, Aristoteles, Metaphysik $\Theta 1$-3 - Von Wesen Und Wirklichkeit der Kraft, GA 33, (Frankfurt-am-Main: V. Klostermann, 1990), 113. Véase en particular el comentario de Heidegger a la frase de Aristóteles "toda potencia es

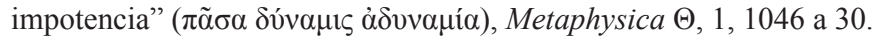


reconocemos la existencia del poder, incluso lo percibimos como algo real, como una propiedad que predicamos de algo o de alguien. Decimos, por ejemplo, que una persona o que una institución tiene poder. Pero esa es una manera engañosa de hablar. Tener poder no es tener cosas. Tener cosas es disponer presentemente y efectivamente de entes que son o están siendo, presentemente y efectivamente, algo. Tener poder es disponer de campo o de espacio para producir lo que no está presente o lo que no es efectivo. Tener poder es tener posibilidad. Y la posibilidad no es, presentemente y efectivamente, nada. No podemos hablar de ella o teorizar sobre ella sin arriesgarnos a desnaturalizarla, a convertir su no ser en ser, en algo que es. En ello radica la dificultad filosófica tradicional del concepto de poder. Sin embargo, porque no es nada en sí mismo o por sí mismo, palpamos la realidad del poder a partir de cosas que efectivamente son, o están siendo, o han podido llegar a ser, o no dejan de ser, y que bien podrían no ser o dejar de ser, perder su poder ser. El poder se modaliza siempre en la ejecución de algo distinto de sí: poder-hacer, poder-vivir, poder-pensar, poder-volar, poder-gozar, poder-gobernar... El poder no es nada en sí mismo y por lo tanto no se lo puede considerar al margen de aquello que ejecuta — aquello en vista de lo cual medimos su poder-. El poder es efectivo y se muestra en la medida en que la indeterminación de una pura posibilidad es determinada y limitada por el fin que ejecuta.

Como le advierte Sócrates a Polo en un pasaje de Gorgias, confundir el poder con una cosa puede traer las consecuencias más nefastas. Nadie niega que el poder ( $\tau$ ò $\delta v ́ v \alpha \sigma \theta \alpha$ ) es un bien, un bien que posee aquel a quien atribuimos poder ( $\tau \tilde{\varphi} \delta v v \alpha \mu \varepsilon ́ v \omega)$ (466b). Pero el poder no es nada en sí mismo, o es pura potencialidad y por lo tanto se muestra

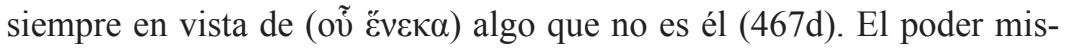
mo es medio, no fin. La confusión contra la que Sócrates nos previene se produce cuando el poder - el medio- es colocado como fin. Entonces deja de haber algo en vista de lo cual el poder pueda medirse y mostrarse como poder. El fin son los medios, y los medios son sin fin. Nos volvemos esclavos de la acumulación infinita o indefinida ( $\sin$ fin) de medios. Y en ese momento se pierde el poder. El tirano mata, despoja, exilia, empobrece, atemoriza... hace lo que le da la gana. Sin embargo, al perder de vista el fin que controla esas ganas, corre el riesgo de engendrar situaciones adversas que le provoquen mal y que lo dejen, a 
la postre, sin poder (468d). Jean-Luc Nancy escribe: “... existe un principio de identidad de la política según el cual el poder no puede (es su impotencia intrínseca) destruir, disolver o devorar aquello sobre lo cual se ejerce. A menos de renunciar a sí mismo". ${ }^{7}$

Más arriba hemos dicho que la producción de conocimiento se realiza sin tener a la vista un fin que organice el proceso productivo. Nadie sabe qué será producido. Como el fin no está dado, es inútil, por otra parte, describir el conocimiento como medio. Ni fin, ni medio, el conocimiento no parece maleable por la vida y el poder. Es de otro orden. Hemos dicho también, empero, que la vida necesita producir conocimiento. El conocimiento es, de alguna manera y paradójicamente, funcional al poder, o al poder-vivir. La paradoja es interesante. La vida y el poder necesitan de aquello que es de otro orden que la vida y que el poder para realizarse y ejercerse como vida y poder.

Supongamos que un grupo de inversionistas quiere producir una droga que luego se venda en el mercado. Es evidente que alguna comprensión, representación o relato acerca de la vida humana y sus fines subyace a dicha iniciativa. Sin embargo, ni los inversionistas ni el relato en cuestión pueden por sí mismos producir la droga. Las leyes del mercado y las representaciones socioculturales de la vida (que las instituciones encarnan) son incapaces de producir ese tipo de objetos. Así maltraten a sus ejecutivos, atemoricen a los investigadores o se coludan con otras compañías, los inversionistas no podrán controlar las entidades y actividades que son específicas para la producción de los objetos que son percibidos por ellos mismos como el fin de sus acciones. Entre estas actividades contamos sistemas y procesos de exposición a lo desconocido, es decir, de aprendizaje, de formación, de estudio, de experimentación, de ensayo, de imaginación, juego, curiosidad y pensamiento. Ni los inversionistas ni los relatos que organizan y dan sentido a sus acciones controlan el curso y las necesidades de estos sistemas, sin los cuales se suprime la posibilidad de conseguir el bien requerido. Y no sólo la droga puede nunca ser producida, sino que una serie de objetos inesperados pueden aparecer accidentalmente mientras se busca desarrollarla (nuevo conocimiento, nuevos instrumentos, nuevos métodos, nuevo capital humano, etcétera). Las leyes del proceso de

${ }^{7}$ Jean-Luc Nancy, Que faire? (París: Galilée, 2016). 
producción de objetos desconocidos (y el pensamiento, la educación, la imaginación...) son contingentes respecto de los relatos institucionales o sociocuturales sobre la vida humana. El poder de los inversionistas no tiene poder sobre las cosas mismas que les devolverán más poder.

Supongamos que líderes políticos desean transformar las universidades en industrias de conocimiento relevante para los fines de la nación. Tarde o temprano se verán confrontados a una paradoja similar a la recién descrita. $\mathrm{O}$ bien instalan sistemas de producción autónomos capaces de engendrar objetos en sí mismos contingentes respecto de los fines previstos, o bien arriesgan suprimir la posibilidad de obtener de ellos los bienes susceptibles de incrementar el propio poder de la nación. Un poder político o institucional que busque evaluar, controlar y capitalizar minuciosamente los procesos de producción del conocimiento destruirá aquello sobre lo cual se ejerce. La voluntad de vivir no basta para poder vivir. Hay que estar dispuesto - y capacitado- a exponerse a lo desconocido.

Los sistemas de producción de conocimiento resisten al poder, resistencia que, sin embargo, es inherente a la producción o autoproducción del poder. El poder necesita de aquello que lo resiste para no dejar de ser lo que es. Es importante notar que lo que así resiste al poder no es, a su vez, otro poder que hace de contrapeso al poder. El poder necesita que la exposición a lo desconocido no se desnaturalice, que siga siendo otra cosa que poder. Pero debemos añadir la fórmula recíproca. Si el conocimiento resiste al poder porque es de otro orden que éste, entonces necesita, a su vez, de poder. Al menos si aspira a no desaparecer; a existir y desarrollarse como conocimiento. ¿Cómo, si no, podrían tener lugar la implementación de procesos productivos de conocimiento, por definición autónomos respecto de la planificación social de la vida? El conocimiento no subiste si no es amparado en una institucionalidad adecuada. Las instituciones dan existencia a interpretaciones del sistema de fines en que se desenvuelve la vida social; determinan y delimitan el ámbito de lo posible, son instancias del poder. Una institución del conocimiento aloja en ella actividades que se desentienden de las interpretaciones del sistema de fines que guían la vida social. Las universidades - entre otras instituciones - cumplen, al menos en parte, con el propósito de alojar en ellas el desarrollo de sistemas de conocimiento 
que resisten al poder o son contingentes respecto de él. Producción de conocimiento y poder se contradicen y a la vez se necesitan mutuamente. Son opuestos co-esenciales el uno respecto del otro. ${ }^{8}$ El desafío de toda institucionalidad para la investigación consiste en darle forma social a esta oposición.

\section{PRODUCCIÓN DE CONOCIMIENTO EN LA UNIVERSIDAD}

La teoría de la evolución por selección natural es muchas veces evocada para justificar agendas ideológicas de desarrollo y crecimiento, cuando no la concentración del poder político y económico en grupos disfuncionalmente minoritarios. Conviene recordar que la selección natural se hace siempre sobre la base de variaciones producidas por azar. La idea es que existe un principio de diferenciación interno a la vida que no obedece a diseño teleológico alguno. En otras palabras, nada de lo que produce la vida es propósito de la vida; pero esta irracional productividad es, ella misma, generadora de los rasgos que sellan la adaptabilidad y sobrevivencia de las especies. Porque actúa sin fines, crea la posibilidad de adaptarse a fines. La vida es cachurera y chapucera por definición. ${ }^{9}$ Ignoro si algún evolucionista se atrevería a explicar la finalidad de la reproducción sexual y de la muerte individual con independencia de contextos de presión. Nosotros mismos, los de género masculino, estamos en trance de volvernos cachureo, como lo enrostra Valery Solanas. ${ }^{10}$ No se conoce la necesidad de enterrar muertos con cráneos de animales hace cien mil años, aunque difícilmente la historia humana es comprensible sin un componente de tanteo simbólico. Tampoco se conoce la finalidad que pudo haber tenido la publicación de la Crítica de la razón pura en un contexto en que el 30 por ciento de la

${ }^{8}$ La resistencia infinita del conocimiento al poder es elocuentemente analizada por Jacques Derrida en La universidad sin condición (Madrid: Trotta, 2002). Lo que este texto deja pendiente es estudiar la dinámica de esta recíproca dependencia o mutuo engendramiento de ambos elementos heterogéneos. ¿Cómo la estructura necesariamente finita del poder y la resistencia infinita del conocimiento se originan y necesitan mutuamente?

${ }^{9}$ François Jacob, "Le Bricolage de l'Évolution", en la antología Le jeu des possibles (París: Fayard, 1981). En inglés: "Evolution and Tinkering", Science 196, n. ${ }^{\circ} 4.295$ (1977): 1.161-1.166. Agradezco al profesor Juan Ormeño haberme sugerido esta conexión con la idea de Jacob.

${ }^{10}$ Valery Solanas, SCUM Manifesto (autopublicado, 1967). 
población no sobrevivía a la infancia y otro 20 por ciento no cumplía los treinta (estadística muy inferior a la de otros países del continente europeo en el mismo momento). ${ }^{11} \mathrm{Ni}$ que a Descartes se le ocurriera el plano cartesiano, que hoy agota la realidad de varios que cultivan profesiones relevantes.

Es cierto que el conocimiento es un instrumento decisivo para la adaptación de la vida humana (toda la interpretación de Nietzsche sobre la emergencia de las ciencias biológicas durante el siglo XIX pone el acento en este aspecto), pero no es cierto que el conocimiento se produzca en vistas de este fin. Cualquier política pública que aspire a proteger el crecimiento y desarrollo del sistema de fines que compone la vida social debe proteger al mismo tiempo la autonomía de la investigación, aun a riesgo de generar pérdidas, de acumular cachureo y de fomentar chapucería. Para emplear una analogía que es tan antigua como poco fortuita y poco inocente, la percepción que debe tenerse del establecimiento de sistemas de producción de conocimiento responde a una lógica similar a la que se tiene de la inversión en capacidad e institucionalidad militar. No conviene esperar a tener que servirse de ella para empezar a implementarla. Por otra parte, no profundizaré aquí en la estrecha y decisiva relación que mantienen investigación y desarrollo militar, porque es inexistente en Chile. ${ }^{12}$ Concentrémonos por ahora en la universidad.

Abandonar la universidad a la presión insufrible de producir lo relevante es una manera tan efectiva de destruir en ella la producción de conocimiento como lo sería abandonarla a la competencia y el cálculo de la inversión en conocimiento de acuerdo con la rentabilidad de los rankings, el marketing y las acreditaciones. El conocimiento no ocurre por arte o magia de la iniciativa política, estatal o privada. Pero de la

11 David Blackbourn, History of Germany, 1780-1918: The Long Nineteenth Century, segunda edición (Oxford: Blackwell Publishing, 2003).

12 Sí sería interesante estudiar algunos casos. Uno más o menos reciente, y que involucra aspectos sociales, económicos, políticos y técnicos de gran interés, es sin duda el de empresas Cardoen y los programas de innovación para Famae durante los años ochenta. En un ámbito distinto, pero igualmente asociado a la historia política y social de la ciencia chilena, existe el extraordinario estudio de Edén Medina sobre el proyecto Cibersyn durante el gobierno de Salvador Allende. Véase Cybernetic Revolutionaries. Technology and Politics in Allende's Chile (Massachusetts: The MIT Press, 2011). 
iniciativa política, estatal y privada sí depende que no se destruya. De ella y sólo de ella cabe esperar que se regulen y consoliden los espacios para que los investigadores que trabajan en las universidades se dediquen a hacer lo que saben hacer.

Conviene distinguir el impacto propiamente académico del impacto social y económico de la investigación. Lo crucial es que no se da el segundo sin que se dé el primero (sí muchas veces lo inverso). No existe manera de calcular de antemano el impacto económico y social de la investigación. Por ejemplo, las pérdidas que produce cada año la creación e instalación de sistemas informáticos defectuosos ${ }^{13}$ superan hiperbólicamente el costo que supuso la producción de los papers de Gödel, Church, y Turing, sin los cuales ningún mandamás de Silicon Valley se habría dedicado a su negocio. De modo similar, sería desacertado medir la calidad de una investigación en ciencias sociales por sus efectos en la opinión o su elegibilidad para participar del diseño de políticas públicas. La investigación genera un sinnúmero de objetos con impacto puramente académico, a veces en comunidades muy pequeñas, pero imprescindibles para el desarrollo y cultivo de las disciplinas.

Es la propia investigación la que debe suministrar la vara con que la sociedad tenderá a medirla. Esa vara es la pertinencia o impertinencia de sus productos desde el punto de vista estrictamente académico y estrictamente científico. Sería imposible concebir un instructivo para generar un sistema de medición. No queda otra que confiar en los investigadores. La sociedad puede contribuir a controlar, eso sí, que éstos se comporten como tales, o que las instituciones les permitan, o los obliguen, a comportarse como tales, dejando a un lado agendas ideológicas o corporativas. Por otra parte, el uso político y social que se haga de las instituciones del conocimiento y de los productos que generen es asunto que compete a la autoridad pública. No es posible pensarlo como parte de los fines que estructuran internamente el establecimiento de sistemas de investigación. Algo parecido podría decirse de la valoración ética que se haga del uso y aplicación de los conocimientos obtenidos, de acuerdo con los diferentes contextos culturales.

Desde luego, es inevitable priorizar y desarrollar algunas disciplinas y áreas en desmedro de otras. Hay muchos criterios para hacerlo:

${ }^{13}$ Gérard Berry, Pourquoi et comment le monde devient numérique (París: Fayard, 2008). 
el impacto social y económico, las urgencias nacionales y regionales, la ubicación geográfica de los establecimientos, la masa crítica y la industria. Hay también razones presupuestarias. Hay incluso razones ideológicas y asociadas a intereses particulares. Sin embargo, para poder desarrollar conocimiento en áreas prioritarias tiene que existir previamente la posibilidad de siquiera realizar una priorización. Eso no se puede si el sistema completo no tiende de antemano al cultivo de todas y cada una de las disciplinas conocidas y por conocer. Además, esta diversidad de disciplinas es inherente a todo sistema de producción de conocimiento y resulta, a la larga, una condición para el éxito de programas específicos de investigación. Más allá de las disquisiciones filosóficas sobre la naturaleza del conocimiento, las disciplinas y áreas son abstracciones necesarias sólo desde el punto de vista de la institucionalidad y gestión de la investigación (por ejemplo, sirven para organizar su enseñanza y difusión). En la práctica, cualquier investigador en cualquier disciplina sabe que no debe presuponer la existencia de compartimentos escolares estancos. La investigación es híbrida y compleja por definición. No se puede anticipar el tipo de disciplinas, de saberes, de instrumentos, de tecnologías, de objetos, de lenguajes, de teorías, de metodologías e incluso de estilos que deben concurrir para desarrollar una investigación. En este terreno, todas las verdades se tocan. Debe ser, en parte, el terreno de la universidad.

Pero, ¿qué es la universidad? La universidad es y existe como idea. Entiendo "idea" en el sentido kantiano del término. Las ideas no son predicados ni expresan propiedades de objetos, y por lo tanto no son susceptibles de manipulación deductiva. Pero las ideas no son meros entes de razón (entes rationis). Son artefactos plenamente existentes (la persona, el deber, la responsabilidad, la libertad, la vida, el poder, el ser humano, la sociedad, el crecimiento, el desarrollo, el territorio, etcétera, son ideas), e incluso, a su modo, eficaces o eficientes (la historia humana ha vivido y vive habitada por ideas...), y más: son horizontes de comprensión imprescindibles para la determinación de los sistemas causales que llamamos "objetos". Kant definía las ideas como totalidades incondicionadas de series infinitas de condiciones. Hegel se percató tempranamente del oxímoron que esta definición contiene (totalidad/infinito). Podríamos decir que la idea de universidad, al igual que la idea kantiana de idea, hace convivir dos sentidos en extremo tensionados 
entre sí: el infinito de la investigación, la acción incondicionada de lo desconocido, por una parte, y, por otra parte, la ejecución de representaciones (totalizantes) del sistema de fines de la vida social (interpreta el mundo y las necesidades profesionales, produce bienes, propone idearios, etcétera). Ambas, sociedad e investigación, obedecen a órdenes y legalidades diferentes que conviven en la universidad.

Es inherente a la institución universitaria el compromiso con una visión del mundo y una misión. La universidad produce comprensiones totalizantes de la realidad. Todas las universidades tienen idearios, no sólo las confesionales. El ideario de las universidades (estatales o privadas, laicas o confesionales) no condiciona por sí mismo la capacidad de contribuir a la producción de conocimiento. Esta afirmación supone que un ideario incapaz de autosuficiencia intelectual, sin vigor para exponerse a la posibilidad de su refutación, temeroso de las opiniones y preguntas que formulen desde la cátedra los investigadores que la institución financia, y que se afane, por último, en separar lo que disiente, no es, en rigor, un verdadero ideario. Un ideario debe tener la vocación de exponerse abiertamente a su cuestionamiento, si es verdad que busca promover un horizonte global de sentido para la sociedad en su conjunto y no para una porción aislada y excepcional.

La libertad de una universidad como institución social se mide por la capacidad de darle realidad pública a su misión o ideario. La libertad de la investigación es otra cosa. De una parte, concierne la capacidad de implementar sistemas de objetivación (ciencias exactas, naturales y sociales); de otra, la capacidad de someter a estudio las representaciones que la vida humana se hace de sí misma (humanidades y artes). La producción de conocimiento se mide por su impacto académico, es decir, por su valoración al interior de comunidades que son, por lo demás, interinstitucionales e internacionales. En sí mismos, los resultados de una investigación no son afectados, mejorados o empeorados por el compromiso ideológico de la institución que los aloja. Que, en la práctica, siempre exista cierto grado de condicionamiento o de contaminación no es atribuible a la lógica de la producción de conocimiento. De hecho, combatir con eficacia fenómenos como la censura y la autocensura supone concebir claramente, y por separado, la naturaleza de la investigación y el contexto institucional en que ésta se aloja. Por último, conviene tener presente que la producción de conocimiento es una acti- 
vidad bastante más antigua que todos los idearios que animan la implementación contemporánea de universidades, incluidas las confesionales. La pura autonomía y libertad institucionales no son garantía de la autonomía y libertad requeridas para la investigación — ni viceversa-.

Un sistema puede hacer convivir proyectos educativos muy diversos o bien desarrollarlos centralizadamente desde el Estado. En el mundo hay ejemplos de experiencias exitosas en ambos modelos. A lo largo de su historia - que tiene la peculiaridad de haber propiciado los dos-, Chile no ha conocido ninguna experiencia exitosa. Cualquiera sea el sistema que en el futuro se adopte, es interés de la sociedad que se tienda a fortalecer los mecanismos de financiamiento y aseguramiento de la calidad con independencia de idearios particulares o estatales. Organismos como Conicyt o la CNA están llamados a jugar un rol esencial como promotores imparciales de la investigación. ${ }^{14}$ El Estado puede financiar la investigación a través de aportes directos a todas las instituciones con capacidad de generarla sin esperar ni temer que ello lo comprometa con alguna visión de mundo. Adicionalmente, convendría reflexionar sobre la necesidad de perfeccionar la carrera de investigador. ${ }^{15}$ Por ejemplo, en los Estados Unidos los académicos pueden aspirar a la "permanencia" ("tenure") en sus universidades, lo que les entrega niveles de libertad y autonomía mucho mayores a los existentes en nuestro país, sin que ello obstaculice la ejecución de idearios o malogre la utilidad social y económica de la investigación.

La universidad de la que hablamos pertenece al mundo "globalizado", "planetarizado". El mundo globalizado es un mundo que existe al mismo tiempo como uno solo y como una multiplicidad irreductible de mundos. Es el mundo de las guerras civiles planetarias. El mundo en que vivimos es uno que se unifica y multiplica al ritmo de la autoproducción y autodiferenciación planetaria de la vida. La globalización no es una idea político-económica regulativa; es el problema del hecho de una coexistencia planetaria transestatal y transhumana, en que la singularidad y la diferencia proliferan incesante e inabarcablemente. La

${ }^{14}$ Los desafíos principales de estas instituciones han sido lúcidamente descritos por Aïcha Liviana Messina en "Universidades en crisis: ¿qué vale el 'publish or perish' en Chile?”, El Mostrador, 22 de abril de 2015. Véase además Manfred Svensson, "El paper y la acreditación”, El Mostrador, 21 de enero de 2016.

${ }^{15}$ Véase Jorge Gibert Galassi, "Ciencia: la única tarea", El Mostrador, 22 de octubre de 2015. 
universalidad de la universidad se encuentra evidentemente comprometida por esa proliferación, y exige de nosotros que la reinterpretemos. La tarea de universalizar ya no puede sólo concebirse como mera producción de insumos universales. Es cierto que el problema ecológico, las migraciones, las crisis económicas, los movimientos sociales, las "guerras contra el terrorismo", etcétera, exigen de nosotros un esfuerzo por crear marcos y artefactos políticos, jurídicos, económicos, entre otros, que tengan eficacia universal. Es cierto que la universidad debe cumplir con la misión de dar acceso y difusión al conocimiento. Pero universalizar es también desarrollar la capacidad de participar del proceso de singularización y diferenciación en que consiste el mundo globalizado. La universidad es producción, cuidado, promoción de singularidad y diferencia. Es lenguaje para lo que no se satisface con nombres heredados, concepto para lo que no se entiende, exploración de lo que significa entender. Al confiarle la tarea de producir conocimiento a una universidad, la sociedad le da existencia social a lo desconocido y se da la oportunidad para vivirlo. Le confía la tarea de producirse ella misma a la vez como universal y singular.

Sin embargo, llamamos también universidades a instituciones que juegan un rol a primera vista mucho más modesto, o en las que la tarea universalizadora es apenas decorativa y la producción de conocimiento, insignificante. Durante las últimas décadas, en el mundo y en Chile, las universidades tienden a concentrar sus actividades en la pura formación técnica y profesional. Se espera de ella que capacite a los agentes productivos, sujetos humanos a los que es preciso inocular una serie de reglas y métodos para la reproducción de objetos conocidos. En los médicos, el conocimiento y la habilidad de sanar; en los arquitectos, el conocimiento y la habilidad de edificar; en los ingenieros, el conocimiento y la habilidad de calcular, etcétera.

Pero la producción de conocimiento no es sólo una actividad entre otras. Es una actividad que permea todas las otras. Los agentes técnicos y profesionales no son artefactos programables que responden a situaciones programables. Son entes humanos de los que se espera actividad creadora en contextos, por definición, inanticipables, expuestos a la proliferación de singularidad y diferencia. Por eso, no basta con instruirlos. Hay que enseñarles también a ejercer correctamente su profesión. Ahora bien, la dificultad de ejercer una profesión no es otra que la de captar 
lo singular y diferente; darles forma de caso para una regla que hay que acomodar, transformar o inventar cada vez. Enseñar a ejercer una profesión es exponer a lo desconocido. ${ }^{16}$

De ello no se sigue que todos los centros de formación técnica (me refiero, en particular, a las universidades que se comportan como tales) deben desarrollar investigación. Y menos que todos los profesionales necesiten tener experiencia en investigación académica. Se sigue que una fuente importante de desigualdad en la calidad de la enseñanza técnico-profesional es atribuible al dispar acceso a contextos en que la producción de conocimiento es asunto real y robusto. Para los futuros técnicos y profesionales, no es lo mismo tener profesores que dedican toda su semana a instruir para pasar exámenes y controles que tener profesores con el tiempo y las condiciones para estudiar lo que no se entiende y no se sabe, solos o en equipo. No es lo mismo estar en instituciones administradas por personas que conocen el quehacer académico que en instituciones administradas por personas que no lo conocen. Hay que tomar en cuenta, entonces, una serie de exigencias para la preparación y selección de académicos y para la estabilidad del sistema en su conjunto, que debe asegurar el acceso a una producción diversa, amplia y compleja de conocimiento. EP

${ }^{16}$ Más sobre esta idea, en Juan Manuel Garrido, Hugo Eduardo Herrera, Manfred Svensson, La excepción universitaria. Reflexiones sobre la educación superior chilena (Santiago: Ediciones UDP, 2012). 